\title{
Proceso de transición en el marco institucional mexicano a través de la comercialización del garbanzo, 1916-1924
}

\author{
Ana Luz Ramírez Zavala*
}

Resumen: la comercialización del garbanzo de Sonora y Sinaloa, de 1916 a 1924, permite mostrar el cambio institucional que se gestó a partir de la incorporación de las medidas creadas por organizaciones y sus agentes intermediarios involucrados en la producción y venta, para reducir los costos de negociación de la leguminosa, en un contexto político y económico coyuntural nacional e internacional. Estas medidas fueron institucionalizadas durante el régimen posrevolucionario, para superar las condiciones adversas para la exportación de este grano.

Palabras clave: garbanzo, marco institucional, organizaciones, cambio institucional, exportación, historia del siglo xx en Sonora y México.

Abstract: chickpea commercialization in Sonora and Sinaloa between 1916 and 1924 shows the institutional change that evolved from the incorporation of strategies to redu-

\footnotetext{
* Estudiante de doctorado en historia, El Colegio de México (Colmex). Chula Vista, C. P. 83296, Hermosillo, Sonora, México. Teléfono (662) 252 0269. Agradezco a la historiadora Astrid Minerva Morales Enríquez por haberme facilitado las fuentes consultadas por ella en el Archivo General del Estado de Sonora (AGES). Correos electrónicos: clioluz@hotmail.com / alzavala@colmex.mx
} 
ce negotiation costs. These measures were advocated by organizations involved in chickpea production and sale, as well as their brokers, during a critical moment in the national and international political and economic context, and were institutionalized during the post-revolutionary regime to overcome the adverse conditions for the export of this grain.

Key words: chickpea, institutional frame, organizations, institutional change, exportation, Sonora and Mexico 20th century history.

\section{Introducción}

John Womack en su artículo, "La economía en la revolución 19101920”, publicado a finales de la década de 1970, advirtió que los historiadores habían descubierto el aspecto económico durante la Revolución Mexicana, para quienes entonces era inconcebible “[...] imaginar que puede haber 'progreso' sin 'orden', producción sin paz. Los estudiosos del decenio revolucionario de México casi invariablemente dan por hecho que, como corresponde a épocas de Revolución (de guerra civil por tanto) no pudo haber entonces en la economía mexicana sino destrucción, trastorno y ruina: un verdadero desastre productivo" (1978). El presente artículo intenta contribuir a la historiografía respondiendo algunas de las preguntas planteadas por Womack, con respecto al impacto que tuvo la violencia en la producción durante la Revolución, a través del estudio de la comercialización del garbanzo de exportación.

Durante las primeras décadas del siglo xx, el garbanzo se cosechaba en Jalisco, Michoacán, Guanajuato, Sonora y Sinaloa. Mientras que la leguminosa de los estados del occidente de México se distribuía en el mercado interno, como alimento y forraje, por su baja calidad, la de Sonora y Sinaloa se exportaba a Estados Unidos, Cuba, Puerto Rico y España; este último país era el principal comprador (Frías 2012, 163). 
En Sonora, los mayores productores de garbanzo se encontraban en los actuales municipios de Álamos, Navojoa, Etchojoa, Huatabampo, Rosario, Quiriego, Cajeme, Bácum y Guaymas. Y en Sinaloa, en los de Guasave, Angostura y Ahome (Ibid., 170). Cabe aclarar que este trabajo profundizará sobre la producción y comercialización del garbanzo en Sonora. Aunque muchas de las medidas y situaciones se aplican para el caso sinaloense, faltó información para hacer generalizaciones sobre las estrategias implementadas en Sinaloa por los actores involucrados en el negocio.

\section{Figura 1}

Municipios productores de garbanzo en Sonora, 1916-1924

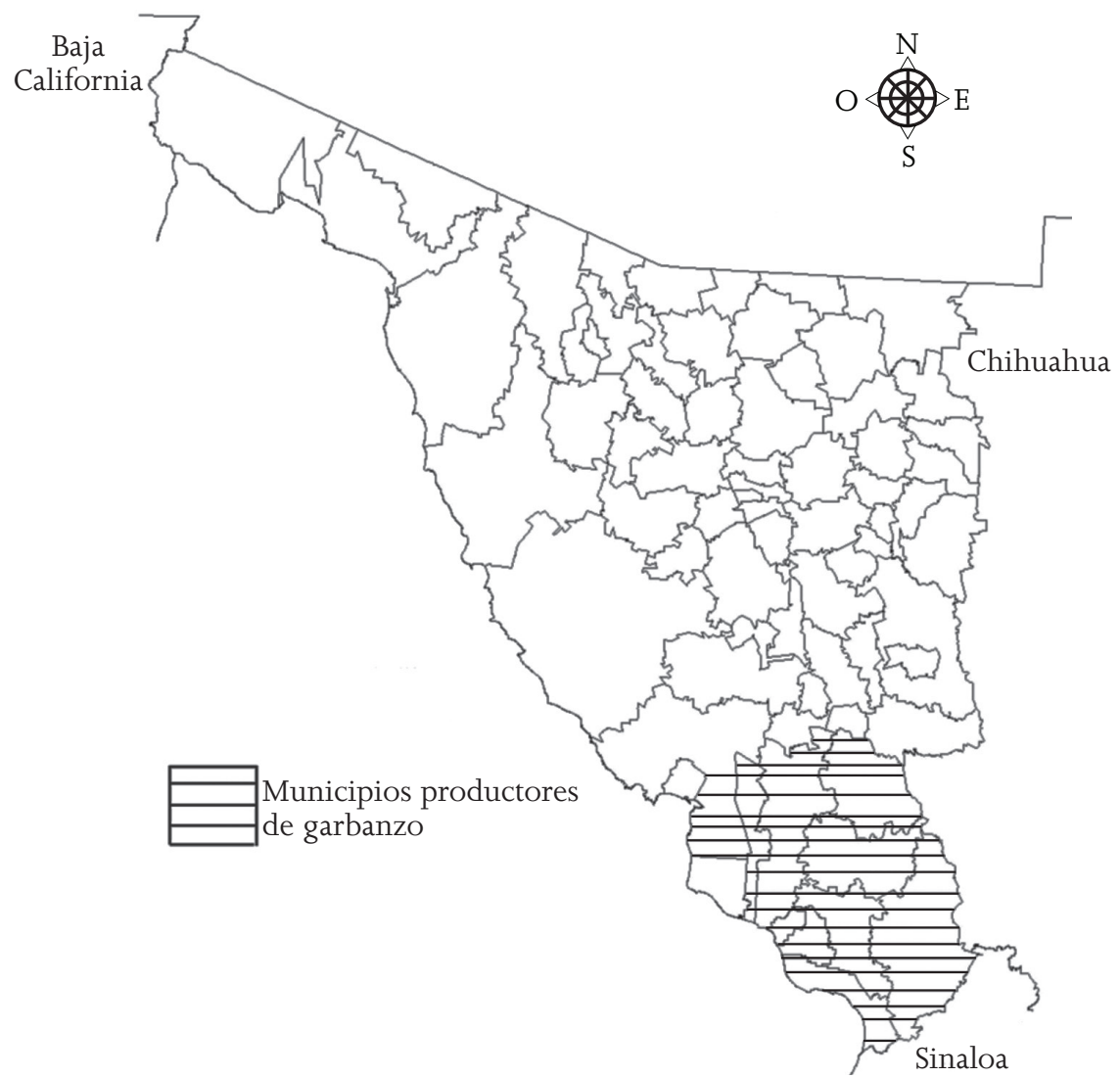

Fuente: AGES, tomo 3190, año1918. 


\section{Figura 2}

Municipios productores de garbanzo en Sinaloa, hasta 1930

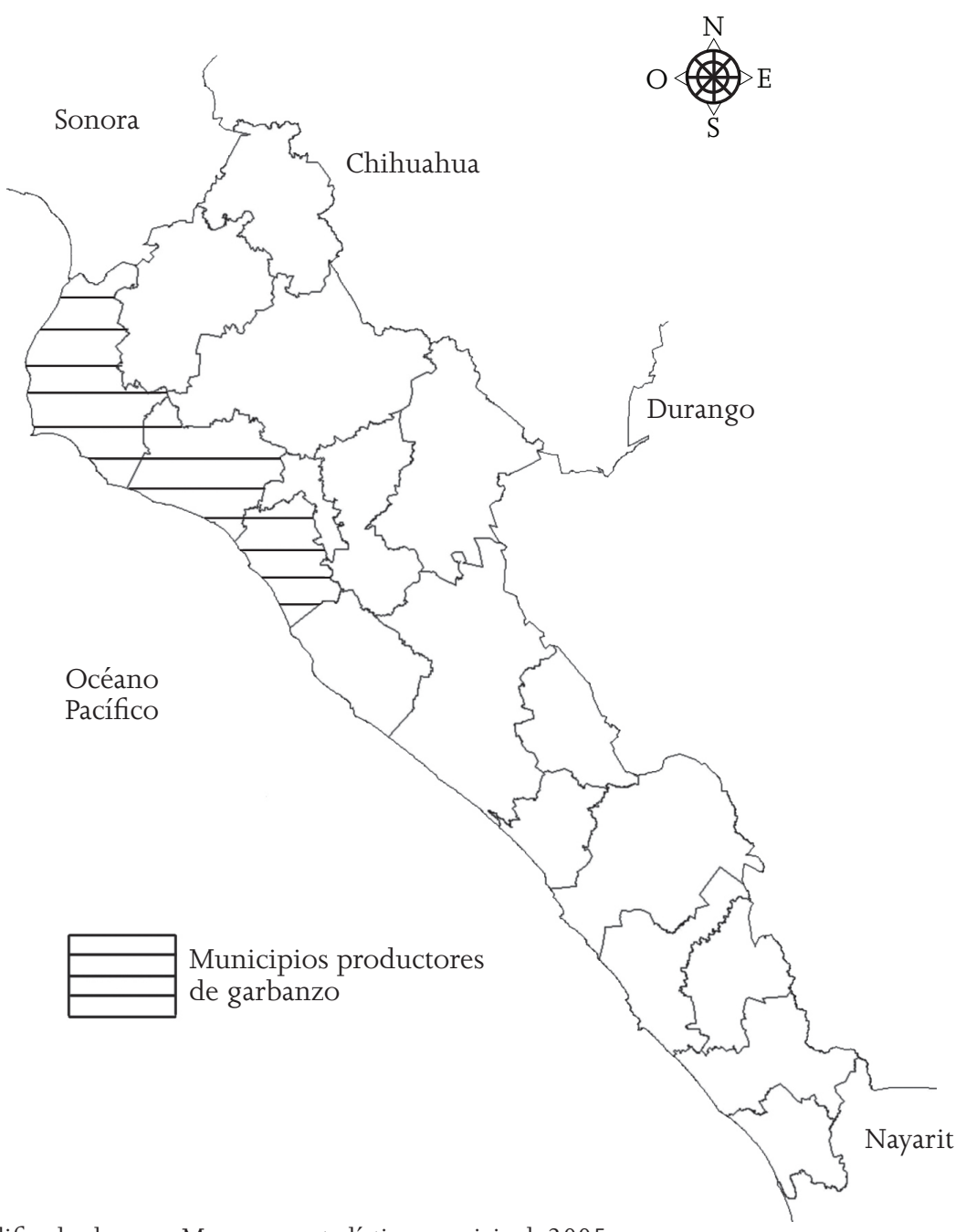

Modificado de INEGI. Marco geoestadístico municipal, 2005.

Fuente: Frías (2012, 170).

Durante los primeros años del constitucionalismo, el garbanzo de Sonora y Sinaloa se benefició por varios incentivos fiscales que no recibieron otros productos agrícolas de la época, como la re- 
ducción del importe por derechos de exportación y la distribución de la tercera parte de éstos entre los municipios productores. ${ }^{1}$ En sesión ordinaria de la Cámara de Diputados, del 1 de septiembre de 1918, se apuntaba que a pesar de estar prohibida la exportación de alimentos se había permitido la venta en el exterior del garbanzo cultivado en Sonora y Sinaloa. La situación económica y política interna, así como las gestiones del general Álvaro Obregón para impulsar a este sector, por tener invertido en él parte de su capital, permitieron el desarrollo empresarial para la producción y comercialización del garbanzo. Sin embargo, después de 1920 los productores de la leguminosa enfrentaron varios obstáculos tales como el embargo, lo que implicaba guardar la cosecha de una temporada hasta que el gobierno permitiera ponerla en venta, con esta medida se trataba de evitar la especulación del precio. Ante este panorama, a simple vista se puede pensar que el régimen constitucionalista fue más benévolo con el sector garbancero que el posrevolucionario, de 1920 a 1924.

El objetivo del presente trabajo es explorar la importancia relativa del marco institucional en la comercialización del garbanzo, conocer el papel que desempeñaron los actores constituidos en organizaciones, implicados en su producción y venta, además de dilucidar "el cambio institucional" a partir de la operación de estos organismos, creados para negociar la leguminosa de manera eficiente a pesar de las condiciones económicas y políticas internas frente a la situación del mercado exterior.

Por marco institucional formal se puede entender las normas creadas por los humanos, que prohíben o condicionan la conducta de los individuos, para realizar ciertas actividades "[definiendo] y [limitando] el conjunto de elecciones de los individuos”. Su función es permitir el intercambio político y económico, favoreciendo el de cierto tipo según la pluralidad de intereses y las estrategias de negociación de los actores, es decir, no necesariamente llega a ser conveniente para toda la sociedad. Las limitaciones informales son los códigos de conducta no escritos, pero respetados y conocidos

\footnotetext{
${ }^{1}$ Cámara de Diputados, 1917-1952. Diario de debates, memoria digital. Legislatura xxviII, año 1, periodo ordinario, diario no 13 .
} 
por la sociedad y el gobierno, inmersos y trasmitidos en la cultura que, de diferentes formas, regulan la conducta de los individuos $y$, en determinado momento, pueden formalizarse. De esta manera, las instituciones y otros factores, como la tecnología, determinan los costos de producción y comercialización (North 1993, 14-68 passim).

Dentro del marco institucional coexisten los organismos u organizaciones, es decir, el escenario en el que interactúan los individuos con intereses comunes desde donde desarrollan "aptitudes, estrategias y coordinación”, para intervenir en la evolución de las instituciones. El objetivo de estas entidades es aprovechar las oportunidades del margen institucional para aumentar los ingresos u obtener beneficios para el negocio; entre instituciones y organizaciones se da una relación de aprovechamiento mutuo y retroalimentación. Douglass C. North apunta que los organismos pueden ser cuerpos políticos, económicos (aquí entran los que intervendrán en el juego de la comercialización del garbanzo como sindicatos, ligas y cooperativas), cuerpos sociales y órganos educativos, y sus integrantes suelen fungir como "agentes del cambio institucional", al tratar de conseguir sus objetivos cambian progresivamente el marco institucional. Aunque, en determinados contextos, las modificaciones dentro de la estructura se producen de manera repentina -como durante una revolución, las limitaciones informales inmersas en la cultura provocan que la trasformación sea progresiva, al reestructurarse las instituciones políticas (1993, 15-99 passim).

Al hacer una revisión superficial de la problemática del garbanzo, como producto de exportación, se planteó como hipótesis preliminar que las autoridades constitucionalistas beneficiaron más al sector garbancero que las del periodo posrevolucionario. La teoría del cambio institucional, propuesta por North, permite entender la interacción entre instituciones y organizaciones, para sancionar la comercialización del garbanzo. Durante el constitucionalismo, etapa de reestructuración política, estas medidas permitieron operar a pesar de la debilidad de las instituciones mexicanas aprovechando la demanda externa, mismas que después las autoridades federales aplicaron para mantener el negocio de la leguminosa, pese a la disminución de su demanda. 


\section{La comercialización del garbanzo durante el constitucionalismo, 1916-1920}

La exportación del garbanzo en Sonora data de finales del siglo XIX, una década después se convirtió en un importante producto de exportación. A partir de 1907, comerciantes españoles compraron el garbanzo sonorense a un precio mayor del que comúnmente se vendía. A partir de 1913 aumentó el volumen de exportación a España debido a que, desde 1912, este país enfrentaba a la resistencia marroquí de la región del Rif, cuyos habitantes se oponían a su protectorado. $^{2}$ El grano también se vendió a Cuba, Puerto Rico y Estados Unidos; este último, además de ser consumidor, desempeñó un papel como intermediario, pues era más económico almacenar el grano y pagar los impuestos de exportación por esta vía, que entre México y el resto de los países que lo consumían (Frías 2012, 165-168).

Durante los años más álgidos de la lucha armada revolucionaria, de 1913 a $1916,{ }^{3}$ a la economía mexicana le perjudicó el descenso en la producción industrial, por el colapso en las inversiones, debido a la confiscación de bienes, así como por el control del sistema ferroviario por las facciones en pugna (Haber 2010, 428).

En el contexto internacional, en 1914 estalló la Primera Guerra Mundial, conflicto que se prolongó hasta 1918, y provocó el alza en el precio internacional de materias primas, debido a su mayor demanda. Así, la necesidad en el mercado externo de ciertos recursos promovió el aumento de las exportaciones de algunos productos como el petróleo, varios minerales, henequén y garbanzo, entre

\footnotetext{
${ }^{2}$ Los agricultores del noroeste estaban acostumbrados a vender la fanega de garbanzo entre 2.00 y 2.50 pesos, a partir de 1907 comerciantes españoles pagaron 5.00 pesos por la misma cantidad (Aguilar 1979, 32-33; Aguilar 2006, 61).

${ }^{3}$ A raíz del asesinato de Francisco I. Madero, el 22 de febrero de 1913, iniciaron las contiendas militares por el retorno a la constitucionalidad, una vez derrocado el gobierno usurpador se revelaron las diferencias de intereses entre los grupos sociales que conformaron las fuerzas revolucionarias. Una vez derrotada la facción convencionista, los vencedores de esta contienda, pertenecientes al sector medio de la sociedad mexicana, fueron incorporando las demandas de las otras fracciones revolucionarias en el Congreso constituyente, para integrarlas en la Constitución de 1917. El nuevo grupo en el poder mostró mayor capacidad de organizar las instituciones del nuevo Estado (Gilly 1980, 21-53).
} 
otros, esto originó que el comportamiento económico de México fuera desigual; hubo crecimiento en regiones exportadoras y estancamiento en otras (Riguzzi 2010, 398; Knight 2010, 1245).

Como se verá más adelante, algunos integrantes de la nueva clase política fungieron como agentes intermediarios haciendo posible el desarrollo, tecnificación y efectividad de determinados sectores productivos, cualidades necesarias para satisfacer la alta demanda en el exterior de ciertos productos por el conflicto mundial. Funcionarios y "caudillos" invirtieron tiempo, dinero y esfuerzo en mantener la marcha y hacer que ciertas actividades prosperaran, a pesar de los conflictos bélicos regionales. Durante el constitucionalismo, los productores, los agentes locales y las autoridades estatales negociaron la forma y los medios para regular los procesos productivos en auge y sobrevivir a la competencia. Entre estos actores se establecieron relaciones clientelares que mantendrían, en los años siguientes, a unos en el poder mientras que la otra parte se benefició con inversión en infraestructura, exención de impuestos y otros privilegios (Merino y Zuleta 2010, 463; Womack 1978).

En Sonora, al cultivo del garbanzo le perjudicó la inestabilidad del contexto político regional, como la presencia prolongada de las huestes villistas; las hostilidades de los yaquis rebeldes, que provocaron que los propietarios de las tierras prefirieran abandonarlas o arrendarlas a los jornaleros, para no arriesgar sus vidas; ${ }^{4}$ la negativa de la Richardson Construction Company a suministrar el agua necesaria para el riego de las tierras significó otro problema para el cultivo de la leguminosa ${ }^{5}$ y las inundaciones que ocurrieron en esa región también dañaron la producción.

Para que los factores internos de la inestabilidad mencionados no perjudicaran al sector agrícola del noroeste de México, el régimen revolucionario otorgó ciertas concesiones a las autoridades estatales,

\footnotetext{
${ }^{4}$ Correspondencia de agricultores de Bácum al gobernador del estado de Sonora (AGES, fondo Ejecutivo, tomo 3118, 15 de mayo de 1917).

${ }^{5}$ En Estación Esperanza y Cócorit, ambos en el valle del Yaqui, hubo quejas de que la Richardson Construction Company no abría las compuertas para el riego de sus terrenos de cultivo. Correspondencia de José M. Herreros al gobernador de Sonora y oficial mayor al presidente municipal de Cocórit, respectivamente, (AGES, fondo Ejecutivo, tomo 3083 y 3084, 26 de mayo de 1916 y 21 de octubre de 1916).
} 
agentes regionales y productores apostando al auge de las exportaciones para obtener recursos. Así, se decretó la disminución de 2 centavos sobre los derechos de exportación por kilo de garbanzo, es decir, el impuesto bajó de 8 a 6 centavos. Además, se dispuso la distribución de la tercera parte de la cantidad recaudada por este concepto entre los municipios productores de Sonora y Sinaloa, ${ }^{6}$ y se nombró a un agente del gobierno por municipio para intervenir en la venta de la leguminosa. Dichas prerrogativas sugieren la debilidad de las autoridades centrales frente al poder de la clase política regional. ${ }^{7}$

Estas disposiciones gubernamentales, en especial la distribución de las recaudaciones de los derechos de exportación del garbanzo sirvieron para que los ayuntamientos invirtieran en obras de infraestructura y riego, tales como reconstrucción de acequias y recomposición de las calles. Otros propusieron al gobierno del estado que aprobara un impuesto sobre la venta del garbanzo, para invertirlo en otras obras públicas; los regidores de Bácum sugirieron aprobar un impuesto de 0.5 centavos oro nacional, para emplearlo en la reparación del canal Porfirio Díaz, que regaba los campos de Cócorit, San José y Bácum. ${ }^{8} \mathrm{Al}$ reducirse los costos de transacción, varios pueblos de Sonora también se beneficiaron al designar ese dinero para la construcción de escuelas. ${ }^{9}$

\footnotetext{
${ }^{6}$ Decreto del 1 de junio de 1916 y circular no. 91 (AGES, fondo Ejecutivo, tomo 3115, 26 de mayo y 1 de junio de 1916).

${ }^{7}$ Enrique Moreno al presidente municipal de Cocórit (Ibid., tomo 3083, 15 de mayo de 1916).

${ }^{8}$ Dicha propuesta fue aprobada, la cual implicaba 0.5 centavos más los derechos de exportación. Después hubo arrendatarios perjudicados con la nueva disposición, ya que vendían su cosecha a terratenientes y otros "especuladores". Un mes después, el mismo grupo de regidores volvió a solicitar el gravamen de 0.5 centavos más, para realizar otras obras públicas, a lo cual no accedió el gobierno del estado. El municipio de Navojoa también gravó con 20 centavos su cosecha (Ibid., tomos 3083; 3118 y 3190, 16 y 26 de abril de 1917; 15, 29 y 30 de mayo de 1917 y 1 de junio de 1918 , respectivamente).

${ }^{9}$ Así lo muestra el siguiente telegrama, recibido por Adolfo de la Huerta en su carácter de gobernador interino de Sonora: "Pte. Municipal de Cócorit, informa que se han comprado dos pipas regadoras, se ha construido un kiosco de ladrillo y otras importantes mejoras y en junio próximo se principiara a construir el edificio para escuelas, todo esto con los dos abonos que ha suministrado el Gobierno [...]" Otros municipios que aprovecharon este entrada de dinero para la construcción de escuelas e infraestructura fueron Bácum y Navojoa (Ibid., tomo 3115 , 11 de octubre y 9 de noviembre de 1916; 21 de febrero, 21 de marzo y 26 de mayo de 1917).
} 
Es posible decir que durante los años de la Revolución, tanto el gobierno constitucionalista como las autoridades estatales apoyaron al gremio garbancero no sólo disminuyendo la cantidad que derogaba los derechos de exportación, sino permitiéndole que una parte del dinero recaudado beneficiara a los municipios productores con la instalación de infraestructura y la construcción de otro tipo de obras públicas. Quizá se pensaba como una inversión a largo plazo de la que luego el gobierno podría echar mano, como sucedió un par de años después para impulsar la agricultura comercial.

La situación internacional se reflejó en la venta del garbanzo, pues su demanda disminuyó durante 1917. El gobierno pretendió confiscar la cosecha de Sonora y Sinaloa, ${ }^{10}$ e intentó la formación de un bloque de cosecheros, lo cual fue rechazado por los garbanceros porque temían la formación de un grupo de acaparadores. Ninguna de las dos medidas proteccionistas se llevó a cabo en ese momento, al gobierno federal no le quedó otra salida que decretar de nuevo la disminución de los derechos de exportación, de 6 a 3 centavos por kilo, para apoyar a los agricultores imponiéndose así los intereses regionales. ${ }^{11}$

En la segunda mitad del mismo año, la postura del gobierno federal y las condiciones del mercado cambiaron, ya que se dejó de suministrar a los municipios productores la tercera parte de los derechos de exportación del garbanzo que les correspondía. ${ }^{12}$ A partir de la Administración de Plutarco Elías Calles, en Sonora se gravó la venta de garbanzo con 2 por ciento, dicho impuesto se utilizaba para pagar el sueldo de los maestros de la entidad, además de la construcción del internado Coronel J. Cruz Gálvez, proyecto de Plutarco Elías Calles para amparar a los huérfanos de la Revolución mediante la enseñanza en artes y oficios. ${ }^{13}$

${ }^{10}$ Adolfo de la Huerta a Ramón J. Uribe (Ibid., tomo 3115, 28 de marzo de 1917).

${ }^{11}$ (Ibid., 1 y 2 de abril de 1917).

${ }^{12}$ Oficial mayor al presidente municipal de Cócorit (Ibid., 1 de junio de 1917).

${ }^{13}$ Correspondencia Plutarco Elías Calles (Ibid., tomo 3191, 22 de noviembre de 1918). La estrategia utilizada por los agricultores, para no verse perjudicados por este nuevo impuesto, fue reportar un menor lote de cosecha. R. Áviles a Plutarco Elías Calles (Ibid., tomo 3115, 5 de julio de 1917). 
Para 1918 la situación del erario en Sonora era crítica, por lo que se decretó un impuesto estatal de 60 centavos por saco de 90 kilos sobre la producción de trigo y garbanzo. Esto según la lógica de que el estado perdía la posibilidad de obtener ingresos al vender el garbanzo en el extranjero:

[...] los impuestos deben gravitar sobre aquellos ramos de riqueza pública que tengan mayor importancia $[\ldots]$ considerando también, que dos de los productos agrícolas que se cosechan en mayor abundancia en el estado, el trigo y el garbanzo no reportan hasta ahora gravamen alguno y por lo tanto, no contribuyen de una manera directa con su respectivo contingente para mejorar las condición económica del estado $[\ldots] .^{14}$

Los agricultores se quejaron agriamente por esta medida considerándola anticonstitucional. Cada municipio solicitó la exención del pago del impuesto estatal, los cosecheros de Bácum pretextaron que, por la presencia de los yaquis, la mano de obra escaseaba en el lugar, y a los pocos trabajadores había que pagarles salarios más altos. El gobierno respondió a estas solicitudes con una negativa, pues de las contribuciones dependía el pago de diferentes rubros del gasto público; además, consideraba que dicho impuesto no era gravoso, pues según sus cálculos el precio de la legumbre había aumentado 300 por ciento en los últimos años. ${ }^{15}$

Por otro lado, a mediados de 1918 se suscitaron varias controversias nuevas en torno al cobro de los impuestos municipales por la venta de garbanzo, quizá porque fue el recurso que les quedó a los ayuntamientos para hacerse de fondos ante las últimas disposiciones de gravar a la legumbre con un impuesto estatal. ${ }^{16}$ El siguiente golpe a este sector agrícola fue la reforma del 19 de mayo de 1919,

\footnotetext{
${ }^{14}$ Decreto 6 A del 11 de mayo de 1918, incluía una multa de 25 por ciento sobre el impuesto para quienes declararan una cosecha menor y otras sanciones (Ibid., tomo 3190, 6 de junio de 1918).

15 (Ibid., tomos 3115; 3190, 5, 7 y 28 de junio de 1918).

16 (Ibid., tomo 3191, 1918 y Fideicomiso y Archivo Plutarco Elías Calles y Fernando Torreblanca (FAPECFT), decretos y circulares del gobernador de Sonora general Plutarco Elías Calles, 1918-1919, tomo IV.
} 
al artículo primero del Decreto $6 \mathrm{~A}$, con la que se modificó la contribución de 60 centavos por saco de 90 kilos a 1 centavo por cada kilo producido. ${ }^{17}$

Tras las fuertes lluvias que azotaron la región y dañaron la cosecha, los agricultores solicitaron la exención del impuesto de producción. Las autoridades respondieron que atenderían su petición cuando iniciara la cosecha de 1920, y que estaría condicionada a la recuperación de la situación económica. ${ }^{18}$ Los enfrentamientos suscitados entre productores, autoridades municipales y estatales se pueden entender en el contexto de una situación económica precaria, que llevó a las autoridades a abusar de los ingresos que podían obtener de actividades pujantes, como era el cultivo del garbanzo en Sonora y Sinaloa.

En 1918, Álvaro Obregón formó la Sociedad Agrícola y Cooperativa de Sonora y Sinaloa, ${ }^{19}$ con la finalidad de otorgar créditos a los cosecheros " $[\ldots]$ incrementar la producción, hacer ventas directas $[\ldots]$ mejorar la semilla [...]" Los miembros de la cooperativa estaban obligados a vender su garbanzo a dicho organismo a cambio de préstamos para financiar el proceso de cultivo. La asociación acaparó más de 70 por ciento de la producción de garbanzo del noroeste de México. Por otro lado, Obregón también fue agente comercial, a través de la agencia aduanal Obregón y Cía. Después se desempeñó como presidente de la Unión de Cosecheros de Garbanzo de Sonora y Sinaloa, encargada de la comercialización de la leguminosa en Estados Unidos y del pago al gobierno de los derechos que arrojaban su producción y venta. Años más tarde se formó el Sindicato de Cosechadores de Garbanzo de Sonora y Sinaloa (sCGSS), en busca de beneficios como la disminución o liberación de impuestos sobre este producto (Aguilar 1979, 426 y 427; 2010, 173-175; Hall 1999, 189-191; Latapí 1991, 173; Grijalva s/f, 4).

Obregón hizo una gira por Estados Unidos para abrir el mercado del garbanzo, consiguió vender la mayor parte de la cosecha de 1918, la cual fue enviada a Europa para apoyar las carencias provo-

\footnotetext{
${ }_{17}^{17}$ Reforma del Decreto 6 A (AGES, fondo Ejecutivo, tomo 3287, 19 de mayo de 1919).

18 Gobernador de Sonora a Alejandro Obregón (Ibid., tomo 3287, 6 de noviembre de 1919).

${ }^{19}$ Gobernador de Sonora a Álvaro Obregón (Ibid., tomo 3190, 3 de julio de 1918).
} 
cadas por la guerra. A decir de Linda B. Hall, el motivo original de la visita del divisionario a Nueva York fue acaparar el mercado de inmigrantes puertorriqueños, potenciales consumidores de dicha leguminosa (1999, 177-179). Otro medida tomada por Obregón, para ampliar el mercado del grano, fue promoverlo en el Departamento de Defensa de Estados Unidos, como alimento para los soldados en campaña. Con estos argumentos, Obregón envió muestras de garbanzo al general James Ryan:

Mi querido y buen amigo: espero que a la fecha estarán ya en su poder los garbanzos que tuve el gusto de enviarles y que habrán resultado del agrado de ustedes. Yo usé varias veces, durante mi campaña por el Bajío del Estado, con muy buenos resultados, llegando a suplir al frijol con una economía de $40 \%$ en volumen. Además el garbanzo tiene un proceso más sencillo económicamente, pues la forma de usarse comúnmente es cocido ya sea con carne de res, cabra o marrano, o en puchero español sin necesidad de manteca como el frijol, y un segundo proceso cocido [...] Si ustedes no disponen de algún cocinero que conozca los procedimientos que se usan comúnmente para cocinar el garbanzo, tendré mucho gusto en enviarles uno para los experimentos. ${ }^{20}$

Después de que este grano fue puesto a prueba por la escuela de cocina del fuerte de Sam Houston, Texas, se decidió adquirirlo para sustituir algunas legumbres secundarias en la alimentación de la milicia estadounidense, pues según los resultados de las pruebas el garbanzo fue más económico en comparación con otros cereales. ${ }^{21}$

Hasta aquí es claro que a pesar de la debilidad que caracterizó a las instituciones del gobierno constitucionalista, si es que así se les puede llamar, hubo un acuerdo de cooperación entre los involucrados en el negocio de la leguminosa y las autoridades, que permitió operar a Álvaro Obregón en una organización como agente comercializador del garbanzo, y lograr beneficios para el gremio que representaba y para el gobierno, al reducir los costos de transacción

20 Álvaro Obregón al general James Ryan, (FAPECFT: 11020500, nombre: Ryan, James a general, expediente "213"/365, inventario 653, 5 de septiembre de 1918).

${ }^{21}$ General James Ryan a Álvaro Obregón, (Ibid., 5 y 7 de octubre de 1918). 
obstruidos por las políticas del país y agravados por las condiciones del mercado exterior (North 1993, 71). En palabras de North, "las oportunidades aprovechables", en este caso, el alza en la demanda del garbanzo en el mercado exterior y la debilidad del gobierno revolucionario en constitución permitieron a los organismos, creados para comerciar el grano, operar de manera que beneficiara y protegiera la comercialización incluso a costa de los agricultores $(1993,20)$.

Por otro lado, llama la atención que los impuestos con los que fue gravado el garbanzo en estos años, afectaron a la producción más que a la comercialización, es decir, al gobierno -tanto al federal, pero quizá en mayor medida al de Sonora- no le interesaba perjudicar el negocio del garbanzo, sino gravar una actividad relativamente exitosa en esta región. Puesto que el grano, como mercancía de exportación fue la excepción a la regla en muchas ocasiones, ya que a pesar de haberse prohibido la exportación de productos alimenticios, éste quedó exento con el argumento de que se consumía poco en el país. Además, para estos años hubo una tendencia a la baja de los derechos de exportación, pues a las ventas de algunos bienes les perjudicaba el alza en los costos de producción. Aunque los derechos de exportación del garbanzo tendieron a bajar, al sector no le beneficiaron varias de las contribuciones impuestas (véase figura 3). ${ }^{22}$

Esta situación se entiende al conocer el contexto de la política arancelaria del comercio exterior de esos años, caracterizada por su desequilibrio, puesto que se gravó con más rigor los productos de exportación en comparación con las importaciones. Que a la mercancía importada se le gravara menos lo explica la carencia de alimentos, que se tuvieron que importar, sobre todo durante los años más agudos de la lucha armada. Por otro lado, la bonanza de las ventas de petróleo, ciertos minerales, textiles y productos agrícolas obligaron a las autoridades a fundamentar la entrada de ingresos al erario público por medio de las exportaciones, con el argumento de

\footnotetext{
22 Según la nueva política económica se decretó, el 13 de junio de 1917, que se gravara la exportación de productos manufacturados como de recursos naturales (Pani 1925, tomo I, 31-32).
} 
que en realidad el impuesto recaía sobre el consumidor extranjero. La política económica del gobierno revolucionario tendió a abrirse hacia el exterior " [...] el coeficiente medio de protección se redujo a 22 por ciento, y se mantuvo por debajo del 20 por ciento hasta 1923.” Después, ante la caída de la demanda de varias exportaciones y, en consecuencia, la disminución en los precios obligaron al

\section{Figura 3}

Derechos de exportación sobre el garbanzo, 1916-1924

\begin{tabular}{|c|c|}
\hline Fecha & Derechos de exportación del garbanzo \\
\hline Decreto del 6 de marzo de 1916 & $8 \notin$ kilo \\
\hline Decreto del 1 de junio de 1916 & $6 \notin$ kilo \\
\hline Circular no. 187 del 2 de abril de 1917 & $3 \notin$ kilo \\
\hline 1919 & Libre exportación \\
\hline Decreto del 22 de junio de 1920 & $2 \notin$ el kilo \\
\hline 1921 & Libre exportación \\
\hline Decreto del 24 de febrero de 1922 & $0.5 \not$ el kilo \\
\hline
\end{tabular}

Fuentes: AgEs, fondo Ejecutivo, tomo 3115, 26 de mayo de 1916; 2 de abril de 1917 y 16 de junio de 1921; AGN, fondo Presidentes, Obregón-Calles, volumen 17, expedientes 103-g-6/1 y 103-9-6/3, 17 de marzo de 1922.

Relación porcentual entre el precio del garbanzo en pesos y derechos de exportación ${ }^{23}$

\begin{tabular}{|c|c|c|}
\hline Año & $\begin{array}{c}\text { Precio del saco de garbanzo } \\
\text { de } 100 \mathrm{~kg} \text { equivalente en pesos }\end{array}$ & $\begin{array}{c}\text { Derechos de exportación en } \\
\text { porcentaje al precio de saco } \\
\text { de } 100 \mathrm{~kg}\end{array}$ \\
\hline 1917 & 19.1 & 15 \\
\hline 1919 & 27.86 & 0 \\
\hline 1921 & 32.64 & 0 \\
\hline 1922 & 17.11 & 3 \\
\hline
\end{tabular}

23 Para conocer el equivalente en pesos del precio del garbanzo, ya que éste aparece en dólares, se consultó: "Paridad promedio del peso con el dólar estadounidense, Cuadro 20.6" (INEGI 1999). 


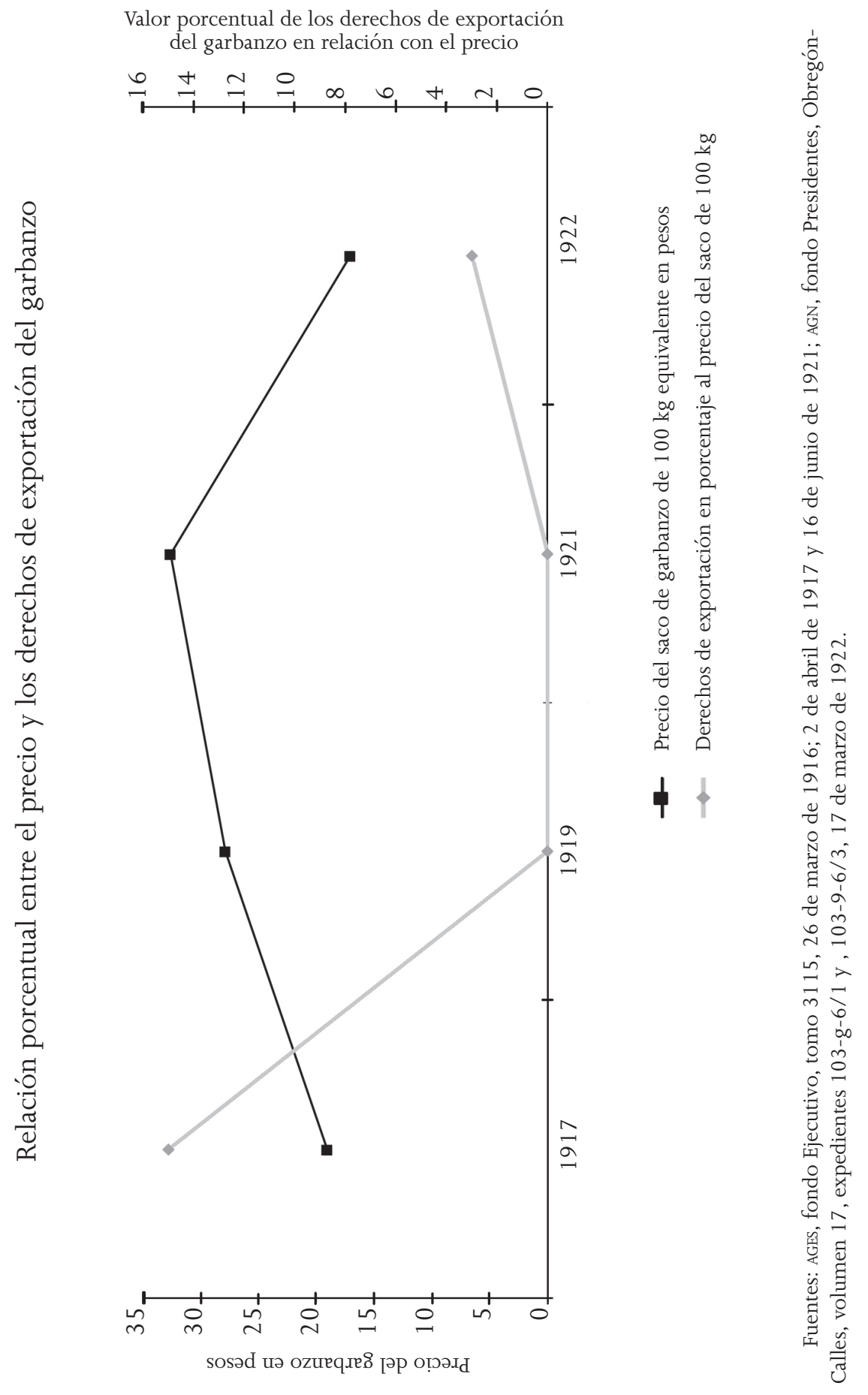


gobierno a subir los aranceles en las importaciones, ya que las exportaciones dejaron de dar los rendimientos suficientes para el pago del gasto público (Collado 1995, 204-205) (véase figura 4).

\section{Figura 4}

Recaudación derogada por los derechos de exportación 1912-1913, 1918 y 1923, según informe de la Secretaría de Hacienda ${ }^{24}$

\begin{tabular}{|r|r|}
\hline Años & Cantidad en pesos \\
\hline $1912-1913$ & 759402.39 \\
\hline 1918 & 8815516.59 \\
\hline 1923 & 21009239.40 \\
\hline
\end{tabular}

El marco formal del periodo constitucionalista, que determinó las reglas del juego con respecto a la comercialización del garbanzo, respondió al intento de restauración de la economía después de una situación de guerra. Las medidas tomadas se pensaron para no detener la marcha exitosa de la economía de exportación, y seguir obteniendo ingresos de ella. En cuanto estas medidas dejaron de funcionar, porque las condiciones favorables del mercado desaparecieron, se impusieron otras. Es evidente la debilidad del poder federal frente a los regionales y locales, al haber cedido los ingresos de la tercera parte de los derechos de exportación para los municipios productores, y no haber ejercido el control de este sector a través de sus propios mecanismos, para regular la comercialización en beneficio del erario federal. Las disposiciones del gobierno constitucionalista, que incentivaron la comercialización del garbanzo, se podrían resumir así: a) el régimen de Venustiano Carranza dispuso dar facilidades para el cultivo de las grandes tierras de labor de las haciendas y ranchos intervenidos; ${ }^{25}$ b) en varias ocasiones se dis-

\footnotetext{
24 FAPECFT; Pani 1925, tomo I, 31-32.

25 Circular (AgEs, fondo Ejecutivo, tomo 3084, 22 de julio de 1916).
} 
minuyó el importe por derechos de exportación (véase figura 3) y c) la tercera parte de los derechos de exportación se distribuyó entre los municipios productores de garbanzo en Sonora y Sinaloa.

La figura de Álvaro Obregón fue fundamental, como agente intermediario, entre las instituciones, los productores de garbanzo, las casas comerciales y los consumidores en el periodo constitucionalista y en los años posteriores. El divisionario como productor, comercializador e intermediario logró entender las necesidades para el desarrollo de la agricultura comercial (Aguilar 1985, 190-1); también impulsó a este sector por tener parte de su capital invertido en él, se puede decir que fue un proyecto personal. Él usó sus conexiones políticas, y luego su posición de poder para trazar el camino para que los organismos, medios técnicos, así como medidas y estrategias para proteger al gremio de la competencia y que las condiciones de mercado se oficializaran; como presidente, impuso estas estructuras organizacionales como condición para que la agricultura comercial pudiera beneficiarse con las instituciones del Estado en construcción.

\section{Institucionalización de las medidas} de comercialización del garbanzo: 1920-1924

Una vez que terminó la Revolución Mexicana y triunfó el constitucionalismo, el general Álvaro Obregón se retiró de la carrera militar y política para dedicarse al negocio del garbanzo en su hacienda, La Quinta Chilla, hasta que ascendió a la Presidencia de la república, después de una accidentada campaña política, debido a las diferencias que tuvo con el entonces presidente Venustiano Carranza.

Obregón estaba comprometido con el sector garbancero, llegó a formar varias organizaciones de cosecheros para mejorar las condiciones de producción y venta de la leguminosa, y así hacer frente a la crisis que sufría el mercado y, por otro lado, tornar benéficas para el gremio las medidas oficiales para obtener recursos, a través de los gravámenes a la producción del garbanzo. Esta experiencia le permitió a Obregón, en el Ejecutivo federal, conocer las condiciones del mercado y darle continuidad al modelo exportador de materias 
primas como política económica. Como se verá más adelante, una de las características de su mandato fue su apoyo al sector agrícola en el afán de modernizarlo, se abocó a dotar de infraestructura y obras públicas a los municipios del sur de Sonora, para disminuir los costos de comercialización.

A partir de 1921 disminuyó la demanda de algunos productos mexicanos de exportación, como consecuencia de la posguerra. Las autoridades federales implementaron varias medidas para amortiguar el déficit comercial, con las cuales se trató de regular la producción (Knight 2010, 492); muchos de estos procedimientos y mecanismos ya se habían aplicado durante el constitucionalismo.

En México, la década de 1920 se caracterizó por la inestabilidad política, provocada por grupos descontentos que no se vieron favorecidos con los cargos políticos que esperaban obtener al triunfo del Plan de Agua Prieta, lo que permitió a otros sectores, como el campesino y el obrero, negociar con las nuevas autoridades la anexión de sus demandas a la agenda política. El gobierno federal logró imponerse gradualmente a los poderes regionales y locales, a través de la creación de diversas instituciones, con apoyo de organizaciones que generaron nuevas estructuras administrativas, como la Reforma Agraria, el ejército profesionalizado, la educación federal y el Partido Nacional Revolucionario, entre otras. Con la Reforma Agraria y los cambios en el ámbito laboral, los gobernantes intentaban hacerse de una clientela para legitimarse en el poder, y contar con ella para enfrentar a sus enemigos. Campesinos y obreros se organizaron en sindicatos o ligas, mediante los cuales el gobierno federal administró el acceso a la tierra y a otros recursos o medió en las relaciones entre patrones y trabajadores (Aboites y Loyo 2010, 595-651).

Obregón, como presidente, volvió a implementar ciertas medidas que se habían puesto en práctica de 1916 a 1918, años en los que la derrama económica que dejó el garbanzo en los valles agrícolas de Sonora y Sinaloa permitió el sostenimiento de la educación y la inversión en obras públicas. Él siguió interesado en impulsar al sector, para ello impuso e institucionalizó varios mecanismos para controlar la comercialización del grano, tales como la asignación de la Comisión Monetaria, para pignorar, es decir, dejar en prenda el garbanzo, almacenarlo y fumigarlo mientras se arreglaba su venta 
en el mercado. La Comisión Monetaria daba 5 dólares por saco al productor, y le cobraba una comisión por su venta e intereses mientras el grano se encontraba almacenado. ${ }^{26}$

Así, durante el cuatrienio presidencial del divisionario, la Comisión Monetaria reguló la comercialización de la legumbre que, además de haber otorgado crédito a los agricultores, asumió otras funciones y actividades necesarias para la venta del garbanzo, que un par de años atrás se habían negociado con organizaciones creadas por los empresarios interesados en dinamizar el negocio del grano. ${ }^{27}$ Sin embargo, existieron otras instancias no oficiales que también prestaron este servicio, como el First Nacional Bank, en Nogales, Arizona, que cobraba menos por sus servicios.

En los primeros años de la década de 1920 descendió el precio de esta legumbre en el mercado internacional, mientras que algunas agencias comercializadoras pretendían vender en España el saco de 100 kilos en 18 dólares, otras lo ofrecieron en 16.50, provocando con esto competencia y especulación en el precio. Además, no había suficientes vagones para embarcar el grano a España, su destino final. ${ }^{28}$ La devaluación de la peseta española fue otro factor adverso para la venta de la leguminosa, y provocó su sobreproducción haciendo imposible acomodarla de una forma fácil y rápida en el mercado. ${ }^{29}$

Aunado a los problemas mencionados, los productores de garbanzo tenían que soportar la carga del almacenamiento, fumigación y la comisión para colocarlo en el mercado, lo anterior hacía menos redituable el negocio, en comparación con los años previos. ${ }^{30}$ Frente a esta situación, la Unión de Cosecheros de Garbanzo de Sonora y

\footnotetext{
${ }^{26}$ Para marzo de 1922, la Comisión Monetaria cobraba por pignoración 1 por ciento mensual de interés. Tomás Robinson a Álvaro Obregón, Archivo General de la Nación, AGN (fondo Presidentes, Obregón-Calles, volumen 17, expediente 103-g-6/1, 8 de marzo de 1922).

27 José Cordero a Adolfo de la Huerta (Ibid., 25 de junio de 1921).

Por decreto del 24 de diciembre de 1924, se ordenó la reforma de que la Comisión Monetaria se constituyera como sociedad anónima (Pani 1925, tomo II, 988).

${ }^{28}$ Aureliano L. Torres, "Informe rendido al consejo consultivo de la Unión de Cosecheros de Garbanzo de Sonora y Sinaloa" (AGN, fondo Presidentes, Obregón-Calles, volumen 17, expediente. 103-g-6/1, enero de 1921.

${ }^{29}$ Salvador Y. Campoy a Román Yocupicio (Ibid., 17 de marzo de 1922).

${ }^{30}$ Aureliano L. Torres, "Informe rendido al consejo consultivo de la Unión de Cosecheros de Garbanzo de Sonora y Sinaloa” (Ibid., enero de 1921).
} 
Sinaloa envió a Aureliano L. Torres como comisionado, para estudiar las condiciones de mercado en las casas comercializadoras de Estados Unidos y España; Torres determinó que el problema radicaba en la competencia y especulación en el precio. La competencia era tan desleal, que algunos tenedores de garbanzo solicitaron al Presidente de la república el aumento de los derechos de exportación a 10 centavos por kilo, para evitar que los especuladores vendieran la cosecha a precios más bajos (véase figura 5) ${ }^{31}$ En este sentido, Torres propuso hacer un convenio entre los tenedores de garbanzo del noroeste de México para fijar un precio unitario, y que fuera sólo una casa comercializadora la encargada de acomodar la leguminosa en el mercado. ${ }^{32}$

\section{Figura 5}

Precio del garbanzo en el mercado internacional

\begin{tabular}{|c|c|}
\hline Año & Precio en dólares \\
\hline 1917 & 10.00 \\
\hline 1919 & 14.00 \\
\hline 1921 & 16.00 (en España) \\
\hline 1922 & $\begin{array}{c}\text { 8.35 (lo que vendió la Comisión Monetaria, } \\
\text { el garbanzo de scGss) }\end{array}$ \\
\hline
\end{tabular}

Fuente: AGEs, fondo Ejecutivo, tomo 3115, 26 de marzo de 1916.

A mediados de 1921, el gobierno dejó libre de derechos de exportación al garbanzo, pero gravó la producción con 1 peso oro nacional por cada saco de 100 kilos, siempre que el valor excediera de 16.00. Al finalizar ese año se ordenó el embargo de la cosecha con el propósito de lograr su venta, que ya se tenía almacenada desde la colecta pasada, para evitar la caída en el precio por la vasta oferta.

${ }^{31}$ Ignacio P. Gaxiola dirigida a Álvaro Obregón (Ibid., 26 de mayo de 1921; José T. Mazón a Álvaro Obregón (Ibid., 27 de mayo de 1921).

32 Aureliano L. Torres, "Informe rendido al consejo consultivo de la Unión de Cosecheros de Garbanzo de Sonora y Sinaloa” (Ibid., enero de 1921). 
Algunos grupos de tenedores del garbanzo solicitaron al Presidente que les concediera permiso para exportar sus lotes, y él contestó que no podía favorecer a ningún grupo por encima de otro:

[...] el permiso de exportación, probablemente, no podrá otorgarse mientras no estén debidamente garantizados los fondos que el gobierno ha invertido por conducto de la misma Comisión Monetaria, ya sea mediante un acuerdo de todos los agricultores para que el garbanzo salga ya vendido y distribuido a los mercados de consumo, y cuando este obtenga de sus compradores un anticipo suficiente para devolver a la Comisión Monetaria los fondos que les ha facilitado. ${ }^{33}$

Con estas medidas, el gobierno federal pretendía obligar a los productores a reunirse en un solo bloque. La presión surtió efecto, puesto que el 24 de diciembre se constituyó el scGss, con el objeto de controlar la venta de garbanzo de la región noroeste, unificar su precio en el mercado y mejorar su calidad. Aunque en realidad sólo llegaron a agrupar a 50 por ciento de los agricultores. ${ }^{34}$ El mecanismo era el siguiente: la Comisión Monetaria realizaría las ventas y también se encargaría de la pignoración y almacenamiento. El agente comercial recibiría 10 centavos de comisión por saco vendido. Tras su constitución, la mesa directiva le solicitó al Presidente que le concediera a la organización la exención de impuestos de exportación, y después que se levantara el embargo, puesto que con la formación de dicha asociación, supuestamente se eliminaban las causas que originaron la confiscación, es decir, la competencia en el

${ }^{33}$ El impuesto a la producción fue una propuesta de Adolfo de la Huerta en su carácter de gobernador de Sonora. Adolfo de la Huerta a Álvaro Obregón (AGEs, fondo Ejecutivo, tomo 3437, 16 de junio de 1921). Correspondencia de Álvaro Obregón a Aureliano L. Torres, representante de la Comisión Agrícola (AGN, fondo Presidentes, Obregón-Calles, volumen 17, expediente 103-g-6/1, 22 de diciembre de 1921).

${ }^{34}$ A pesar de haber sido una consigna para Aureliano L. Torres, quien fue comisionado por Álvaro Obregón para convencer a los productores a integrarse al sindicato, no logró la unificación de todos los tenedores: “[...] Lamento no haber conseguido la 'completa unión' como tanto lo deseaba y que con tanto empeño procuré; pero los poquísimos faltantes son elementos fuera del alcance de mi influencia personal.” Aureliano L. Torres a Álvaro Obregón (Ibid., expediente 103-g-6/4, 29 de enero de 1922). 
mercado que provocaba las fluctuaciones en los precios. ${ }^{35}$ Después, los tenedores del sCGSS vieron los beneficios de embargar el grano, puesto que solicitaron al gobierno la incautación de la cosecha de 1922. ${ }^{36}$ Lo anterior, en detrimento de los productores no sindicalizados, quienes al mismo tiempo pedían que se retirara la orden de confiscación.

Como se puede observar, durante el mandato de Álvaro Obregón se oficializaron algunos de los mecanismos, medios y medidas que durante el constitucionalismo ciertas organizaciones habían creado para reducir los costos de comercialización de la leguminosa; como fue la institucionalización del scGss, cuyo antecedente fue la Sociedad Cooperativa de Agricultores, ${ }^{37}$ que en su tiempo desempeñó el papel de "agente de cambio institucional”. La interacción entre instituciones y organismos determinaron la dirección de los cambios institucionales, al darse un proceso de retroalimentación. Así sucedió en 1918, tres años después se adoptó como mecanismo de control de la comercialización del garbanzo para reducir la incertidumbre (North 1993, 18-19).

Durante la presidencia del general Obregón hubo otros agentes intermediarios -como Aureliano Torres- encargados de estudiar las condiciones del mercado, con el objetivo de determinar las medidas convenientes que el scGss debía de gestionar con el gobierno, para que el negocio del garbanzo siguiera siendo lucrativo para las autoridades y los agricultores. A partir de entonces comenzó a configurarse una división entre los productores agremiados y los que no lo estaban, dicho en otros términos inició la separación entre el sector privado y el público. Aquí cabe preguntarse si los productores, que se mantuvieron dentro de los mecanismos de control del gobierno federal, fueron favorecidos por las autoridades frente a los que se

35 Próspero Ibarra a Álvaro Obregón (Ibid., expediente 103-g-6/1, 15 de diciembre de 1921). Acta constitutiva del Sindicato de Cosecheros de Garbanzo de Sonora y Sinaloa (Ibid., 24 de diciembre de 1921). Mesa directiva del scGss a Álvaro Obregón (Ibid., 30 de diciembre de 1921). Aureliano L. Torres a Álvaro Obregón (Ibid., expediente 103-g-6/4, 29 de enero de 1922).

${ }^{36}$ Aureliano L. Torres a Obregón (Ibid., expediente 103-g-6/2, 6 de febrero de 1923).

${ }^{37}$ La Sociedad Cooperativa de Agricultores fue fundada a principios de 1918, y clausurada en octubre del mismo año. Manuel P. Estrada (FAPECFT: sección 111020500, nombre, Estrada y Cía. Manuel P., expediente 2349/136, inventario 424, 1918). 
quedaron al margen, o si en realidad las condiciones del mercado no dejaban otra solución para reactivar el comercio de este grano. Para responder a estos cuestionamientos es necesario poner sobre la mesa la forma en que operaron los garbanceros no sindicalizados.

Los tenedores de garbanzo que no se integraron a las instituciones oficiales para la comercialización del grano las buscaron en Estados Unidos, para pignorarlo y almacenarlo. Por lo tanto, tuvieron que exportar la legumbre para almacenarla en Nogales, Arizona, mientras se levantaba el embargo para después reimportarla a México, donde se embarcaba en los puertos de Guaymas y Yavaros, para conducirla a su destino final. ${ }^{38}$ De esta manera se ahorraban gastos de transacción y eran mayores sus márgenes de ganancia. Los tenedores siempre se manifestaron en contra del embargo, pues para ellos la venta del garbanzo en la época de cosecha y la competencia que se generaba elevaba su precio. ${ }^{39}$

Como una forma de coerción a los productores no sindicalizados, el gobierno federal prohibió la exportación para la reimportación, así obligaba a las corporaciones no oficiales a integrarse al sistema; ${ }^{40}$ además, a cumplir el embargo, y que el garbanzo que cruzaba la frontera no fuera vendido en agencias comercializadoras estadounidenses; quienes no respetaron la confiscación fueron acusados de contrabando. ${ }^{41}$

De esta manera, es posible estar de acuerdo en que el objetivo de algunas de las medidas implementadas por las autoridades federales eran que el sector garbancero siguiera siendo redituable, como el embargo con el cual se consiguió el establecimiento de un precio unitario. Por otro lado, el hecho de que hubiera detractores de las formas oficiales para comerciar el grano, implicaba que se podían hacer mejores negocios fuera de las instituciones de gobierno, pues percibían ganancias más altas vendiéndolo por sus propios medios.

\footnotetext{
${ }^{38}$ Bracey Curtis a Álvaro Obregón (AGN, fondo Presidentes, Obregón-Calles, volumen 17, expediente 103-g-6/1, 29 de abril de 1922).

${ }^{39}$ Cámara Agrícola y Comercial del Río Mayo a Álvaro Obregón (Ibid., expediente 103-g6/2, 5 de febrero de 1923).

40 Bracey Curtis a Álvaro Obregón (Ibid., expediente 103-g-6/1, 29 de abril de 1922).

${ }^{41}$ Hubo dos lotes de garbanzo que fueron exportados por la aduana de Veracruz durante el tiempo del embargo. R. Arizmendi a Álvaro Obregón (Ibid., expediente 103-g-6/3, 8 de septiembre de 1922).
} 
Así lo decía un miembro de la Cámara Agrícola y Comercial del Río Mayo, cuando se llevó a cabo una votación con respecto al embargo del garbanzo de la cosecha de 1923: "[...] que con la libre exportación venden con más provecho su grano a los agentes foráneos, que pagan siempre mejores precios que los acaparadores locales." En este sentido, se puede decir que estas formas de comercialización, impuestas por el gobierno posrevolucionario, estaban pensadas para controlar la venta del garbanzo y obtener más beneficios, que para apoyar a los productores. ${ }^{42}$ La confiscación del garbanzo, que se proyectó para 1923, provocó división en la Cámara Agrícola y Comercial del Río Mayo (Gracida 2004, 6), ya que unos estuvieron a favor del embargo mientras que otros se opusieron, por lo cual se procedió a someter la solicitud a votación. El resultado fue 44 votos en contra y 39 a favor. ${ }^{43}$

Las autoridades federales trataron de beneficiar a algunos productores, en detrimento de los que comerciaban el garbanzo fuera de las instituciones oficiales. Sin embargo, los tenedores que lo hacían dentro del sistema también resultaron perjudicados por la depreciación del grano en el mercado externo. El marco institucional posrevolucionario estaba estructurado para obtener recursos del proceso de comercialización, aunque no hubiera condiciones favorables en el mercado para su venta, en perjuicio de los agricultores. Así lo reconocía el presidente Álvaro Obregón:

[...] pero venta [de garbanzo] está efectuándose entre ocho y nueve meses después, durante los cuales han pagado agricultores interés pignoración por todo tiempo transcurrido y almacenaje también por mismo lapso. -Creo que cubierta pignoración y todos gastos no sobrará ni un dólar para agricultores.- No es por

\footnotetext{
42 Resultado de la encuesta abierta por la Cámara Agrícola y Comercial del Río Mayo entre sus socios, para conocer la opinión de la mayoría sobre la inconveniencia de solicitar o no del gobierno la retención de la próxima cosecha de garbanzo (Ibid., 28 de octubre de 1923).

${ }^{43}$ Cámara Agrícola y Comercial del Río Mayo a Álvaro Obregón (AGN, Fondo Presidentes, Obregón-Calles, volumen 17, expediente 103-g-6/2, 6 de febrero de 1923); Resultado de la encuesta abierta por la Cámara Agrícola y Comercial del Río Mayo entre sus socios, para conocer la opinión de la mayoría sobre la inconveniencia de solicitar o no del gobierno la retención de la próxima cosecha de garbanzo (Ibid., expediente 103-9-6/3, 28 de octubre de 1923).
} 
demás hacerte saber que en cosecha vendiese año pasado, por cuenta Casa Grace, fue el fracaso tan grande, que productores tienen que devolver ahora alrededor dos dólares por saco del dinero que recibieron como anticipo y ello [...] agrava más situación tan importante gremio esa Entidad. ${ }^{44}$

Los beneficios que obtenía el gobierno federal al establecer los mecanismos y las instituciones de comercialización, como fue la sindicalización, el embargo y la imposición de medios para vender el producto, a través del la Comisión Monetaria, fueron la recaudación de los intereses generados por el embargo que tenían que pagar los garbanceros. En este sentido, ante la disminución en las exportaciones, el gobierno tuvo que obtener ingresos gravando la producción. Sin embargo, lo recaudado se invertía para impulsar al sector agrícola, por ejemplo el acondicionamiento del puerto de Yavaros y el tendido de una línea de ferrocarril de ahí hasta Álamos, pasando por el valle del Mayo, a principios de 1922. Para ello, se les propuso a los beneficiados que apoyaran con la instalación de los durmientes, a cambio de acciones de la compañía ferroviaria. El tendido de las vías férreas en esta región estaba pensado para favorecer, en especial, al sector agrícola del Mayo, pues con el paso del ferrocarril se lograría abaratar los costos de comercialización. ${ }^{45}$ Las siguientes disposiciones tuvieron el mismo objetivo: a) la instalación de una planta de esterilización en Guaymas. El garbanzo pignorado se remitía a este puerto para fumigarlo, así se ahorraba 50 por ciento del costo; ${ }^{46}$ b) las negociaciones para suprimir o reducir los derechos arancelarios que causaba la importación de garbanzo

\footnotetext{
${ }^{44}$ Esta es la respuesta del presidente Obregón con respecto a una petición de Adolfo de la Huerta, en su carácter de gobernador de Sonora, al sugerirle que grabara la legumbre con 50 centavos por saco, para pagar el salario atrasado a los maestros de Sonora. Álvaro Obregón a Adolfo de la Huerta (Ibid., expediente 103-g-6/1, 31 de marzo de 1922).

${ }^{45}$ El secretario de Hacienda fue severamente cuestionado por algunos miembros del Congreso, con respecto al gasto de más de 2 millones de pesos correspondiente al costo del proyecto de construcción de esta línea de ferrocarril. Dicha decisión no fue consultada a la Cámara de Diputados (Cámara de Diputados 1917-1952, Legislatura xxx, año II, periodo ordinario, 25 de octubre de 1923, diario no. 26).

${ }^{46}$ Correspondencia de Álvaro Obregón a José Calderón (AGN, fondo Presidentes, ObregónCalles, volumen 17, expediente 103-g-6/1, 7 de julio de 1921).
} 
a España; ${ }^{47}$ c) la inversión de fondos del gobierno en la Comisión Monetaria; ${ }^{48} \mathrm{~d}$ ) el descuento de 50 por ciento de todos los productos nacionales de exportación que se transportarán por el ferrocarril Sud-Pacífico ${ }^{49}$ y e) la creación del Banco Refaccionario de Occidente y establecimiento de una red telefónica en el río Mayo, a través de la Cámara Agrícola y Comercial del Río Mayo (Gracida 2004, 7).

De esta manera, se puede decir que durante el Gobierno de Obregón las condiciones externas para comercializar el garbanzo no eran favorables, debido a la disminución en el precio y en la demanda. Sin embargo, el gobierno federal implementó e impuso varias medidas para incentivar, reactivar y sostener el negocio de este grano, como la fundación del sCGSs; la imposición de un precio fijo; el embargo de la cosecha; la pignoración, fumigación, almacenamiento y venta por la Comisión Monetaria, así como sanciones para los productores que no se integraron a los mecanismos de control. Así ocurrió la corporativización de una parte de este sector, lo cual representó beneficios para quienes se afiliaron a dichos mecanismos, además de que generó ingresos para el gobierno (Kuntz 2007, 357).

Es evidente que durante este periodo imperó una mayor estabilidad política en relación con la época constitucionalista, que se vio reflejada en la institucionalización de las medidas tomadas por las organizaciones creadas para comercializar la legumbre, pues aunque el barco del negocio del garbanzo se hundía ante las condiciones del mercado, los mecanismos de control del poder federal permitieron que la industria se mantuviera a flote.

En los años posteriores se desplomó la demanda del garbanzo a un tercio del volumen producido, previo a la crisis internacional de 1929 (Merino y Zuleta 2010, 458). En la década de 1930 la producción y comercialización del garbanzo de Sinaloa superó a la de Sonora, para entonces el mercado se había ampliado a América Central y a Filipinas, Brasil y Argentina (Frías 2012, 165-168).

\footnotetext{
${ }^{47}$ Los comerciantes importadores de garbanzo pedían la supresión del arancel argumentando que el principal consumidor era la clase obrera, y que existía un déficit en la producción de garbanzo español. Correspondencia de Alessio Robles (Ibid., 12 de septiembre de 1921).

${ }^{48}$ Correspondencia dirigida a Aureliano L. Torres por Álvaro Obregón (AGN, f. Presidentes, Obregón-Calles, vol. 17, exp. 103-g-6/1, 22 de diciembre de 1921).

49 Álvaro Obregón a Amado Aguirre (Ibid., volumen 164, expediente 424-g-9, 4 de julio de 1924).
} 


\section{Consideraciones finales}

La comercialización del garbanzo de 1916 a 1924 soportó vaivenes políticos y económicos, endógenos y exógenos, que impactaron el desarrollo y éxito del sector. Por un lado, durante los primeros cuatro años de este estudio las condiciones del mercado fueron propicias para la exportación del garbanzo, debido a la demanda elevada y a los precios altos en que fluctuó por las condiciones de guerra imperantes en Europa y España, su principal consumidor.

Por otro lado, de 1916 a 1920 en México se vivía una crisis institucional por el resquebrajamiento del viejo orden político, que generó inestabilidad, la cual se vio reflejada en la debilidad del poder federal frente a los estatales, al ceder los beneficios derivados del garbanzo a los estados productores, ya que el gobierno constitucionalista no generó mecanismos que regularan su comercialización, circunstancia aprovechada por las autoridades regionales para hacerse de recursos financieros. Debido a esas condiciones, a dicho régimen le fue imposible crear disposiciones para incentivar al sector, si bien se hizo durante los dos primeros años de la Administración de Venustiano Carranza, para los dos siguientes la industria garbancera se abandonó a la suerte de los gobiernos estatales, los cuales buscaron la manera de obtener recursos a costa de los productores de la región. En este sentido, se puede decir que durante los años del mandato de Carranza las óptimas condiciones del mercado salvaron el negocio del garbanzo, frente al débil marco institucional que generaba la inestabilidad política de México. Además, cuando la situación del mercado dejó de ser propicia, se crearon organismos cuyos integrantes buscaron reducir la incertidumbre y los costos de negociación del garbanzo, como la Sociedad Cooperativa de Agricultores, entre otras.

En el periodo presidencial de Álvaro Obregón se inició la reestructuración de las instituciones, y a la par se reorganizó el sistema económico del régimen porfirista. La presidencia del sonorense se caracterizó por formalizar los mecanismos ya probados por él, como agente intermediario, para optimizar la comercialización del garbanzo, tales como la fundación del scGss, la imposición de un precio fijo, el embargo y el desarrollo de los medios para vender el 
producto, entre otras. También creó varias disposiciones para disminuir los costos de transacción, como inversión en infraestructura y obras públicas en beneficio de las regiones agrícolas de Sonora.

Sin embargo, de 1920 a 1924 las condiciones del mercado del garbanzo no fueron favorables, es decir, había sobreproducción, baja demanda y el precio había disminuido. Aunque la situación era pésima, los mecanismos implementados por el gobierno federal permitieron la obtención de recursos de esta leguminosa a costa de los productores.

En el periodo de estudio hubo cambios con respecto a la demanda externa del garbanzo producido en Sonora y Sinaloa, en un contexto de transición política en México. En este trabajo se mostró cómo las medidas creadas por los organismos constituidos por los actores implicados en el negocio del garbanzo fueron adoptadas después en el marco institucional posrevolucionario, para convertirse en formas oficiales de control, promovidas por las autoridades, para reducir los costos de comercialización de la leguminosa.

Recibido en mayo de 2012 Aceptado en agosto de 2012

\section{Archivos}

Archivo General de la Nación

Archivo General del Estado de Sonora

Fideicomiso Archivos Plutarco Elías Calles y Fernando Torreblanca

\section{Bibliografía}

Aboites, Luis y Engracia Loyo. 2010. La construcción del nuevo Estado, 1920-1945. En Nueva historia general de México, coordinado por Erik Velásquez et al., 595-651. México: COLMEX. 
Aguilar, Gustavo. 2006. Fuentes y mecanismos de financiamiento para la agricultura de exportación en el valle de Culiacán (19201950). En Agricultura comercial, empresa y desarrollo regional en el norte de México, coordinado por Arturo Carrillo y Mario Cerutti, 61-86. Culiacán: Universidad Autónoma de Sinaloa (UAS).

y Jesús Méndez Reyes (coordinadores). 2012. Debates sobre el noroeste de México. Agricultura, empresas y banca (1906-1940). México: UAS-Universidad Autónoma de Baja California (UABC).

Aguilar, Héctor. 1985. Saldos de la Revolución. México: Océano. Siglo xxI.

1979. La frontera nómada: Sonora y la Revolución Mexicana. México:

Brading, David A. (coordinador). 2010. Caudillos y campesinos en la Revolución Mexicana. México: Fondo de Cultura Económica (FCE).

Cámara de Diputados. 1917-1952. Diario de debates, memoria digital.

Collado, María del Carmen. 1995. Empresarios y políticos, entre la restauración y la Revolución, 1920-1924. México: Instituto Nacional de Estudios Históricos de las Revoluciones de México.

Instituto Nacional de Estadística, Geografía e Informática, INEGI. 1999. Estadísticas históricas de México. México: INEGI.

Frías Sarmiento, Eduardo. 2012. Regiones productoras y vías de comercialización del garbanzo en Sinaloa (1920 a 1940). En Debates sobre el noroeste de México. Agricultura, empresas y banca (1906-1940), coordinado por Gustavo Aguilar y Jesús Méndez Reyes. México: UAS-UABC.

Gilly, Adolfo, Arnaldo Córdova, Armando Bartra, Manuel Aguilar Mora y Enrique Semo. 1980. Interpretaciones de la Revolución Mexicana. México: Nueva Imagen. 
Gracida, Juan José. 2004. Política pública e intereses privados. Desarrollo agrícola del valle del Mayo de Sonora, 1920-1928. En Memoria del segundo Congreso de historia económica. México: Universidad Nacional Autónoma de México (UNAM).

Grijalva Díaz, Ana Isabel. s/f. La reestructuración de la banca y el crédito agrícola en Sonora después de la Revolución, 1918-1934. http://www.economia.unam.mx/cladhe/registro/ponencias/151_abstract.pdf (2 de septiembre de 2012).

Haber, Stephen. 2010. Mercado, industrialización y banca, 18901929. En Historia económica general de México: de la Colonia hasta nuestros días, coordinado por Sandra Kuntz, 411-436. México: COLMEX.

Hall, Linda B. 2010. Los jefes sonorenses de la Revolución Mexicana. En Caudillos y campesinos en la Revolución Mexicana, coordinado por David A. Brading, 161-179. México: FCE.

1999. Álvaro Obregón. Poder y revolución en México, 1911-1920. México: FCE.

Knight, Alan. 2010. La Revolución Mexicana. México: FCE.

Kuntz, Sandra (coordinadora). 2010. Historia económica general de México: de la Colonia hasta nuestros días. México: COLMEX.

2007. El comercio exterior de México en la era del capitalismo liberal, 1870-1929. México: COLMEX.

Latapí, Paulina. 1991. La testamentaria de Álvaro Obregón en una época de crisis. Estudios de Historia Moderna y Contemporánea de México (14): 159-176. http://www.historicas.unam.mx/moderna/ ehmc/ehmc14/185.html (23 de abril de 2012).

Merino, Daniela y María Cecilia Zuleta. 2010. Una visión del campo.Tierra, propiedad y tendencias de la producción, 1850-1930. En Historia económica general de México: de la Colonia hasta nuestros días, coordinado por Sandra Kuntz, 437-472. México: COLMEX. 
North, Douglas. 1993. Instituciones, cambio institucional y desempeño económico. México: FCE.

Pani, Alberto. 1925. Memoria de la Secretaría de Hacienda y Crédito Público correspondiente a los años fiscales de 1923-1924-1925 presentada por el C. secretario de Hacienda Ing. Alberto J. Pani al H. Congreso de la Unión con especial referencia al periodo comprendido entre el 26 de septiembre de 1923 y el 31 de diciembre de 1925, tomos I y II.

Riguzzi, Paolo. 2010. México y la economía internacional, 18601930. En Historia económica general de México: de la Colonia hasta nuestros días, coordinado por Sandra Kuntz, 377-409. México: COLMEX.

Velásquez García, Erik, Enrique Nalda, Pablo Escalante, Bernardo García, Bernd Hausberger, Oscar Mazin, Dorothy de Estrada, Carlos Marichal, Alfredo Ávila, Luis Jáuregui, José A. Ortega y J.Vázquez. 2010. Nueva historia general de México. México: ColmeX.

Womack, John. 1978. La economía en la Revolución (1910-1920). Historiografía y análisis. Nexos I (1 1): http:/ /www.nexos.com.mx $/$ ?P=leerarticulo\&Article=265701 (8 de septiembre de 2012). 